\title{
3. Note regarding an experiment suggested by Professor Robison
}

\section{Prof. J.D. Forbes}

To cite this article: Prof. J.D. Forbes (1849) 3. Note regarding an experiment suggested by Professor Robison, Philosophical Magazine, 35:234, 95-96, DOI: 10.1080/14786444908646315

To link to this article: http://dx.doi.org/10.1080/14786444908646315

曲 Published online: 30 Apr 2009.

Submit your article to this journal ๘

Џ Article views: 1

Q View related articles $\longleftarrow$ 


\section{Note regarding an Experiment suggested by Professor Robison.}

In his memoir of Dr. Chalmers, lately read to this Society, Mr. Ramsay has referred to an experiment which Dr. Chalmers was anxious to have performed on the tide-wave in the Bay of Fundy. The object was to determine the earth's density by the attraction of the tide-wave on a plummet or spiritlevel, on the same principle as Maskelyne's experiment on Schiehallion, but with the superior advantages arising from the perfect homogeneity of the attracting mass, and from the circumstance that all the observations might be made at a single station. 'The experiment might, in short, appear to unite the advantages both of Maskelyne's and Cavendish's methods of determining the earth's density.

The suggestion was Dr. Robison's, and Dr. Chalmers had it from him. It is contained in the Elements of Mechanical Philosophy, edit. 1804, page 339, and is given in the following words :- "Perhaps a very sensible effect might be observed at Annapolis-Royal in Nova Scotia, from the vast addition of matter brought on the coast twice every day by the tides. The water rises there above 100 feet at spring-tide. If a leaden pipe a few hundred feet long were laid on the level beach at right angles with the coast, and a glass pipe set upright at each end, and the whole filled with water, the water will rise at the outer end, and sink at the end next the land as the tide rises. Such an alternate change of level would give the most satisfactory evidence. Perhaps the effect might be sensible on a very long plummet, or even a nice spiritlevel."

It is needless to observe that the methods proposed by Dr. Robison are not the best which might be suggested; but that, in consequence of the extreme simplicity of the observation, considered as a purely astronomical one, a deviation of the direction of gravity of only a very few seconds could be ascertained within small limits of error*.

I thought it worth while to make the calculation approximately for an assumed height of the tide-wave. Had the result been at all encouraging, I should have taken pains to ascertain, on good authority, the exact rise of the tide, and the circumstances of the locality whence the rise is greatest.

* The micrometric observation of a plumb-line, as in a zenith sector, would be sufficient; or, as Professor Smyth has suggested to me, the view of the wires of a transit-instrument, with a collimating eye-piece, as reflected in a mercury trough, -an observation, the accuracy of which may, he states, be brought within one-twentieth of a second. 
I have calculated the horizontal attraction of a semicylinder of water 100 feet thick, and of about two, four, and eight miles radius upon a point at the extremity of the axis of such a semicylinder; because these conditions can easily be reduced to calculation, and because they represent very approximately the circumstances of an attracted point placed at high watermark on a vertical sea-wall facing a basin or estuary. The radius of the attracting mass of water being represented (more accurately) by $10,000,20,000$, and 40,000 feet, I find the influence of a tide-wave 100 feet thick upon a plumb-line to produce a deviation of only $0^{\prime \prime} \cdot 44$ (forty-four hundredths of a second), $0^{\prime \prime} \cdot 50$, and $0^{\prime \prime} \cdot 53$; the effect increasing extremely slowly with the radius, as might be expected. If the tide rose only fifty feet, the first effect would be reduced to $0^{\prime \prime} \cdot 24.6$.

Even the greatest of these calculated deviations affords no ground for hoping that the method of Robison could be applied with any success to determine the earth's density.

It is rather singular that this ingenious suggestion is not once alluded to, so far as I am aware, by any writer on the figure and density of the earth; yet surely it was as worthy of notice as Dr. Hutton's proposal to measure the attraction of an Egyptian pyranid. (Phil. Trans. 1821.)

\section{On a Simple Apparatus for Washing Precipitates.} By Eustace C. Summers*.

MY attention has been lately drawn to an account by $\mathrm{M}$. II Bloch, given in the May Number of the Annales de Chimie et de Physique, vol. xxvi. p. 126, 3rd series, of a new method of washing precipitates by means of a self-regulating siphon. The instrument proposed by M. Bloch is, however, open to several serious objections. In the first place, as soon as the requisite quantity of water has been supplied to the filter, the water rises in the exterior air-tube to the level of the liquid in the vessel from which the supply is obtained. Now if the precipitate be very light, part of it also is liable to gain access to the tube and adhere to its sides. Again, when the level of the water in the filter falls, the column of water in the air-tube does not always fall so as to leave free access to the air. On the contrary, the whole or part of it is frequently carried upwards by the pressure of the air, and falls, not into the filter, but into the reservoir; and should any of the precipitate be carried with it, which is far from improbable, of course an analysis might be at once invalidated. I say

- Communicated by the Author. 